\title{
PERANCANGAN APLIKASI DATA SISWA SMA PERTIWI 1 PADANG MENGGUNAKAN BAHASA PEMROGRAMAN JAVA NETBEANS 7.1.1
}

\author{
Elmawati $^{1}$, Nofriadiman ${ }^{2}$, Zaiva Valevi Uslamarta ${ }^{3}$ \\ ${ }^{123}$ Sistem Informasi, Sekolah Tinggi Teknologi Industri Padang \\ Email : elmawati@sttind.ac.id
}

\begin{abstract}
ABSTRAK : Pengolahan data siswa merupakan suatu kegiatan dalam mengolah data-data siswa yang mana memiliki 2 tahap yaitu penginputan data dan penyimpanan data. tahap pertama yaitu penginputan data yaitu memasukkan data-data siswa yang telah didapatkan ke dalam suatu sistem pengolahan data siswa tersebut. tahap kedua yaitu penyimpanan data yaitu melakukan penyimpanan terhadap data-data siswa yang telah di masukkan tadi. Pengolahan data siswa juga dilakukan di SMA Pertiwi 1 Padang, namun disini permasalahan yang dihadapi yaitu pengolahan data siswa tersebut masih menggunakan sistem manual yang dirasa kurang efektif dan efisien dari pengunaannya, karena pengolahan data siswa tersebut akan mengalami kesulitan dalam 2 tahap pengolahan data siswa yaitu sulitnya menginputkan data secara cepat, tepat, akurat dan penyimpanan data siswa yang keamananya kurang terjamin. Untuk mengatasi masalah yang ada pada SMA Pertiwi 1 Padang dalam mengolah data siswa, maka dibutuhkan suatu sistem baru untuk mengolah data siswa SMA Pertiwi 1 Padang tersebut.
\end{abstract}

Kata Kunci : Perancangan, Aplikasi, data

\begin{abstract}
Student data processing is an activity in processing student data which has 2 stages of data input and data storage. the first stage is inputting data that is entering the student data that has been found into a student data processing system. the second stage of data storage is to store the data of students who have been entered earlier. Student data processing is also done in SMA Pertiwi 1 Padang, but here the problem faced is the data processing students are still using the manual system that is perceived less effective and efficient of use, because the data processing students will have difficulty in 2 stages of student data processing that is difficult input data quickly, precisely, and accurate data storage and students who are less secure security. To solve the problems that exist in SMA Pertiwi 1 Padang in processing student data, then needed a new system to process data of SMA 1 Padang student.
\end{abstract}

Keywords: Design, Application, data

\section{PENDAHULUAN}

Penggunaan sistem manual pada masa sekarang dirasa masih banyak memiliki kelemahan diantaranya yaitu kurang efektif dan efisien jika dilihat dari segi penggunaan sistem tersebut, proses kerja yang lebih lambat dari sistem komputerisasi, serta memperlambat proses kerja lainnya. salah satunya yaitu pengolahan data siswa, jika dilihat dalam penggunaan sistem manual mungkin akan mengalami kesulitan dalam proses pengolahan data siswa yang memiliki 2 tahap proses yaitu penginputan data dan penyimpanan data. Jika pada penginputan data siswa kesulitan yang dialami yaitu sulitnya untuk menginputkan data secara cepat, tepat dan akurat. Jika pada penyimpanan data kesulitan yang dialami yaitu masih lemahnya keamanan dalam penyimpanan data tersebut.

SMA Pertiwi 1 Padang merupakan salah satu Sekolah Menengah Atas Swasta yang ada di Kota Padang Sumatera Barat, yang pada tiap tahunnya selalu menerima siswa-siswa baru. Data siswa baru tersebut di simpan ke dalam penyimpanan data siswa SMA Pertiwi 1 Padang, yang mana data siswa baru ini diambil dari formulir 
data siswa yang sudah di isi oleh siswa baru tersebut saat mendaftar ke SMA Pertiwi 1 Padang.

Selama ini SMA Pertiwi 1 Padang melakukan pengolahan data siswa menggunakan sistem manual yang dirasa masih banyak memiliki kelemahan yaitu sistem manual akan mengalami kesulitan dalam proses pengolahan data siswa yang memiliki 2 tahap proses yaitu penginputan data dan penyimpanan data, yang mana dalam penginputan data terdapat kesulitan dialami yaitu sulitnya untuk menginputkan data secara cepat, tepat dan akurat, dan penyimpanan data yaitu masih lemahnya keamanan dalam penyimpanan data tersebut.

Dalam mengatasi kesulitan yang dialami dalam pengolahan data siswa yang memiliki 2 tahap proses yaitu penginputan data dan penyimpanan data, maka dibutuhkan suatu sistem yang baru yang bisa menginputkan data siswa secara cepat, tepat dan akurat dan memiliki keamanan yang terjamin pada penyimpanan data siswa

Dengan merancang suatu aplikasi menggunakan Bahasa Pemrograman Java yang memiliki kelebihan dari sistem manual, agar dapat membantu lebih cepatnya proses pengolahan data siswa baik dalam segi proses penginputan data dan penyimpanan data.

Berdasarkan Latar Belakang diatas, maka dapat di tentukan masalah yang ada pada SMA Pertiwi 1 Padang yang menggunakan sistem manual, yang mana sistem tersebut masih memiliki kelemahan yaitu Pengolahan data siswa di SMA Pertiwi 1 Padang menggunakan sistem manual dirasa akan mengalami kesulitan dalam 2 tahap proses pengolahan data tersebut yaitu penginputan data dan penyimpanan data, yang mana dalam penginputan data terdapat kesulitan yang dialami yaitu sulitnya untuk menginputkan data secara cepat, tepat dan akurat, dan dalam penyimpanan data yaitu masih lemahnya keamanan dalam penyimpanan data siswa tersebut.
Agar penulisan ini lebih terarah dan tidak terjadi kesalahan serta sesuai dengan tujuan yang diinginkan, Maka penulis hanya membatasi masalah pada pengolahan data siswa SMA Pertiwi 1 Padang yang menggunakan sistem manual.

Dari permasalahan yang dialami oleh SMA Pertiwi 1 Padang yang tertera pada Latar Belakang dan Identifikasi Masalah, maka penulis menentukan Rumusan Masalah yaitu Bagaimana cara merancang aplikasi data siswa yang akan digunakan dalam pengelolahan data siswa SMA Pertiwi 1 Padang.

Tujuan yang akan dicapai dari hasil penelitian ini yaitu Merancang aplikasi data siswa yang akan digunakan dalam pengolahan data siswa SMA Pertiwi 1 Padang dan membuat Laporan Data Siswa.

\section{METODOLOGI PENELITIAN}

Jenis Penelitian yang Penulis gunakan yaitu Penelitian Terapan (Action Research) dan Penelitian Perpustakaan (Library Research). Penelitian Terapan (Action Research) adalah kegiatan yang dilakukan untuk memecahkan masalah yang mana kegunaannya bersifat praktis, yaitu untuk mengatasi persoalan yang harus segera dipecahkan, sedangkan Penelitian Perpustakaan (Library Research) adalah Penelitian yang dilakukan dengan cara peneliti memeriksa bahan-bahan yang telah ditulis oleh orang lain.

Variabel penelitian yang digunakan oleh penulis yaitu variabel pengamatan pada proses pengolahan data siswa sampai selesai.

Pengumpulan data yang dilakukan oleh peneliti dalam penelitian ini terdapat 2 data yaitu Data Primer dan Data Sekunder. Dalam pengumpulan Data Primer ini peneliti menggunakan metode observasi pada SMA Pertiwi 1 Padang, Data Primer yang dikumpulkan berupa data-data siswa SMA Pertiwi 1 Padang. Sedangkan Data Sekunder didapatkan dari studi-studi dan kepustakaan. 
Metode penelitian yang dilakukan peneliti dalam melakukan penelitian yaitu diantaranya:

1. Menyediakan segala keperluan untuk merancang aplikasi data siswa

2. Mengambil data-data siswa ke SMA Pertiwi 1 Padang

3. Menyediakan software dalam suatu bahasa pemrograman untuk membangun sebuah Aplikasi Program seperti Netbeans IDE 7.1 dengan Bahasa Pemrograman Java yang bertujuan untuk merancang Aplikasi Data Siswa yang akan digunakan dalam proses pengolahan data siswa

4. Setelah Aplikasi tersebut dirancang maka dimasukan lah data-data siswa ke dalam Aplikasi tersebut

5. Melakukan Implementasi pada Aplikasi yang sudah dirancang dengan tujuan untuk memastikan Aplikasi tersebut dapat berfungsi sebagai alat untuk mengelolah data siswa SMA Pertiwi 1 Padang

\section{HASIL DAN PEMBAHASAN Implementasi Sistem}

- Menu Login

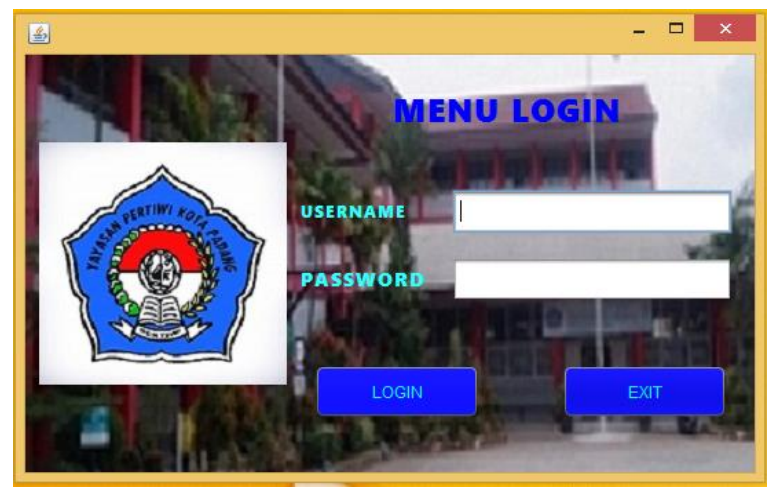

Gambar 1 Tampilan Menu Login
- $\quad$ Menu Utama

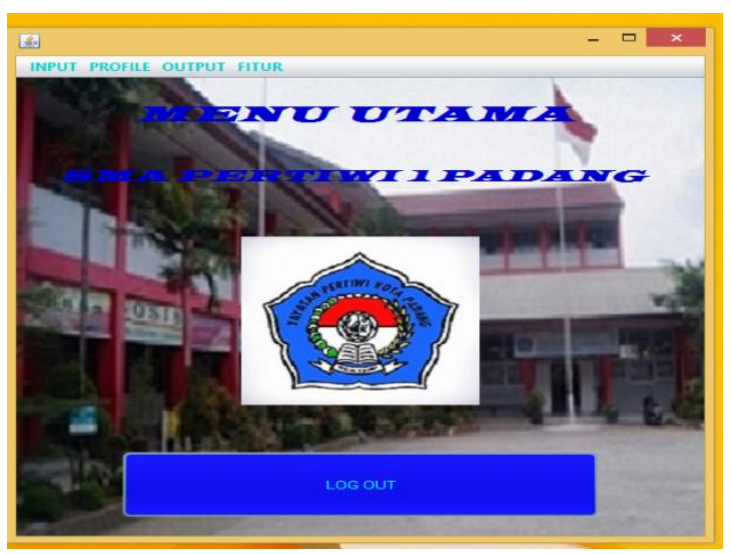

Gambar 2 Tampilan Menu Utama

- Menu Data Siswa

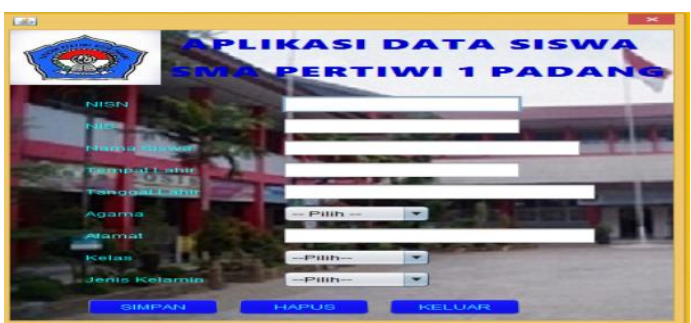

Gambar 3 Menu Data Siswa

- $\quad$ Menu Tabel Data

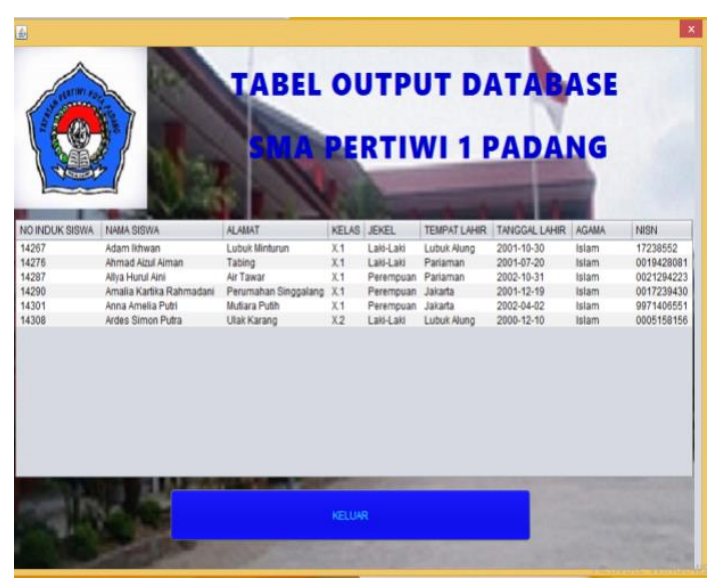

Gambar 4 Menu Tabel_Data 
- Menu Profil SMA Pertiwi 1 Padang

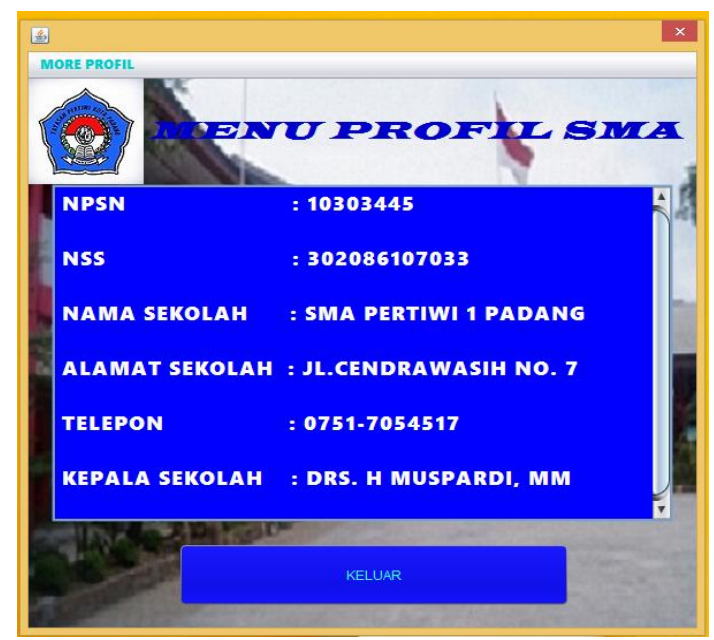

Gambar 5 Menu Profil SMA Pertiwi 1 Padang

- Menu Sejarah

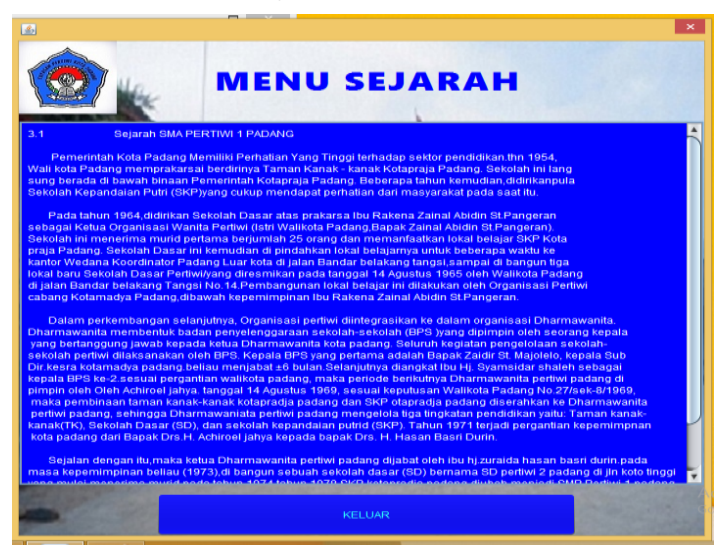

Gambar 6 Menu Sejarah

- $\quad$ Menu Visi Misi

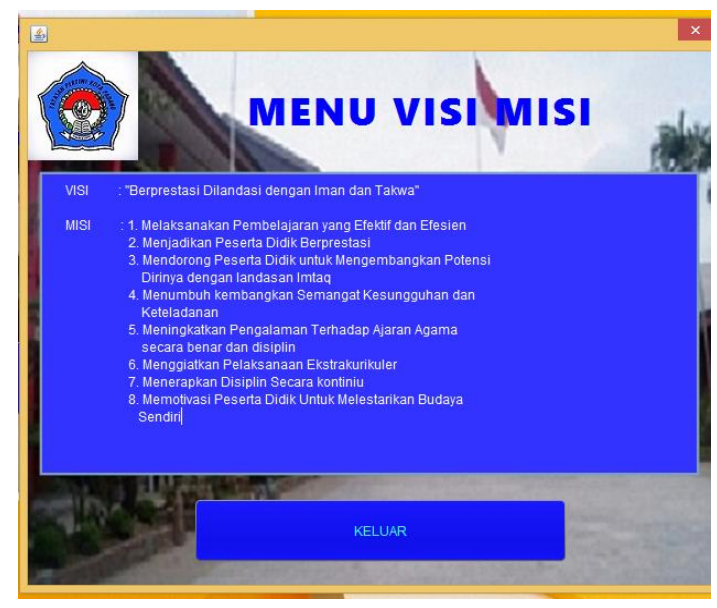

Gambar 7 Menu Visi Misi
- Menu Susunan Organisasi

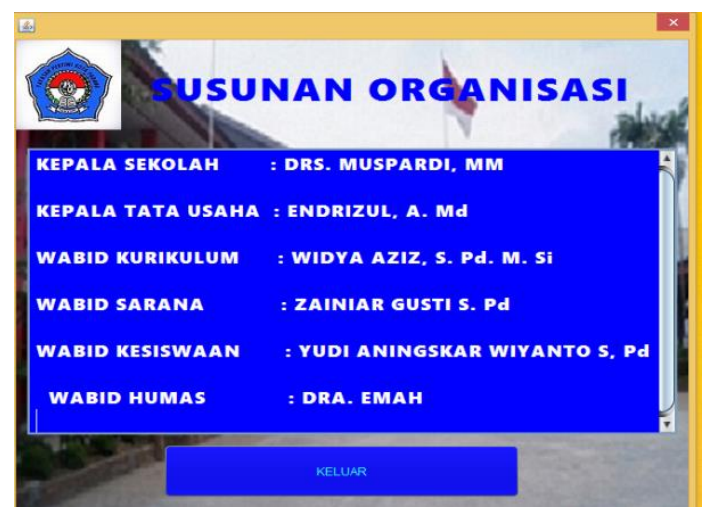

Gambar 8 Menu Susunan Organisasi

- $\quad$ Menu Report 1

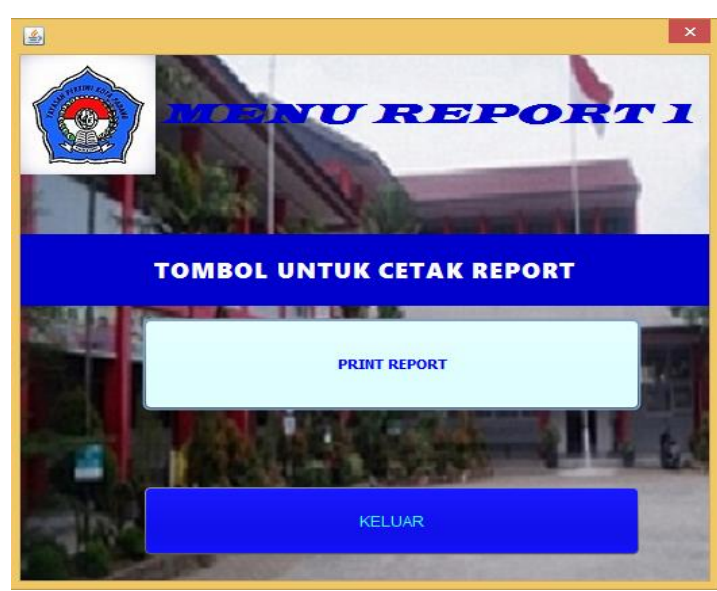

Gambar 9 Menu Report 1

- Tampilan Report 1

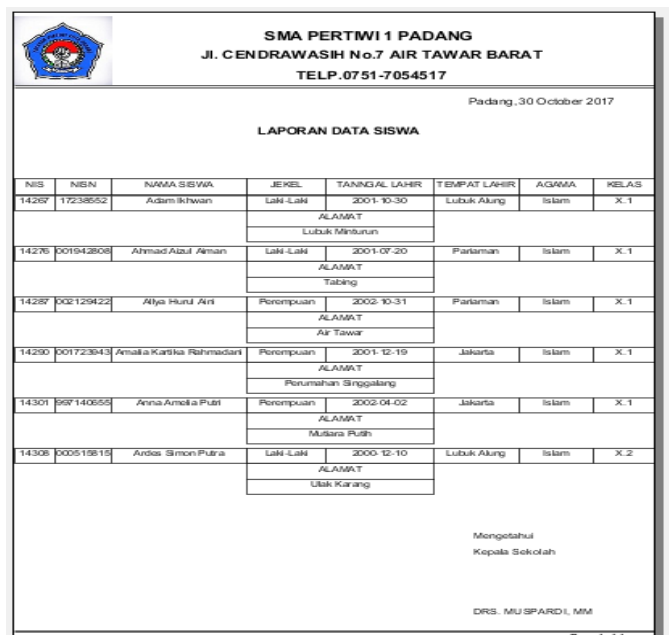

Gambar 10 Tampilan Report 1 
- $\quad$ Menu Report 2

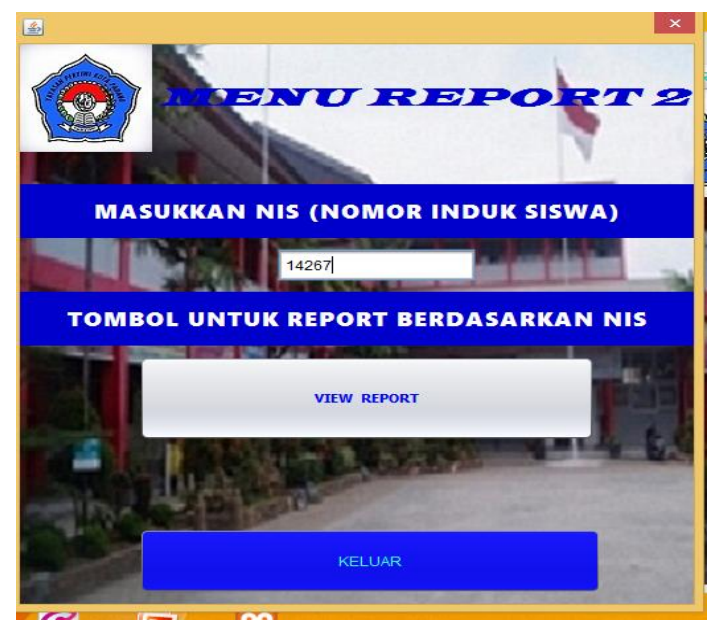

Gambar 11 Menu Report 2

- $\quad$ Tampilan Report 2

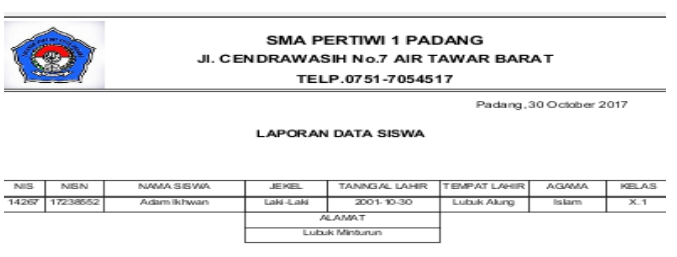

Gambar 12 Tampilan Report 2

\section{KESIMPULAN}

Berdasarkan hasil penelitian pada perancangan aplikasi data siswa, maka penulis menarik kesimpulan, yaitu sebagai berikut : Merancang aplikasi data siswa yang akan digunakan dalam pengolahan data siswa SMA Pertiwi 1 Padang dengan Bahasa Pemrograman Java Netbeans 7.1. Membuat Laporan Data Siswa.

\section{DAFTAR PUSTAKA}

Bambang Hariyanto, Esensi-esensi Bahasa Pemrograman Java, Informatika, Bandung, 2005.

Fatansyah, Basis Data. Informatika, Bandung, Andi, 1999

Hidayattullah, SM, YY, Alat Bantu Perancangan Sistem Informasi, 2016

Ian Leonardo, Pemrograman Database Dengan Java", Elex Media Komputindo, Jakarta, 2004

Mardiani, Eri, Panduan Java Netbeans, Yogyakarta, Andi, 2008

Shintanirmalasari, Pengertian Database dan manfaatnya. 2016.

Sugiri, S. H, Pengelolahan Database MYSQL dengan PHP MyAdmin. Yogyakarta, Graha Ilmu, 2008

Wahana Komputer, Membuat Aplikasi Profesional dengan Java, Penerbit elek media komputindo, Jakarta, 2005 